\title{
Quartz micro-balance and in situ XPS study of the adsorption and decomposition of ammonia on gold, tungsten, boron, beryllium and stainless steel surfaces
}

\author{
M. Ben Yaala ${ }^{1}$, L. Marot ${ }^{1}$, R. Steiner ${ }^{1}$, L. Moser ${ }^{1}$, G. De \\ Temmerman $^{2}$, C.Porosnicu ${ }^{3}$, C. Lungu ${ }^{3}$, M. Oberkofler ${ }^{4}$ and E. \\ Meyer $^{1}$ \\ ${ }^{1}$ Department of Physics, University of Basel, Department of Physics, CH-4056 Basel, \\ Switzerland \\ 2 ITER Organization, Route de Vinon-sur-Verdon, CS 90 046, 13067 St Paul Lez \\ Durance Cedex, France \\ ${ }^{3}$ National Institute for Laser, Plasma and Radiation Physics Atomistilor 409, \\ Magurele, Jud Ilfov 077125, Bucharest, Romania \\ ${ }^{4}$ Max Planck Institute for Plasma Physics, Boltzmannstr. 2, 85748 Garching, \\ Germany
}

E-mail: marwa. benyaala@unibas.ch

\begin{abstract}
.
Gas seeding is often used in tokamaks to reduce the power load onto the divertor target plates. Nitrogen is the preferred seeding species because of its favourable radiative properties as well as its apparent beneficial effect on plasma confinement. However, nitrogen molecules are chemically reactive with hydrogen and its isotopes to form stable ammonia compounds. Since ammonia is a polar molecule, sticking on metal surfaces can be expected, increasing as a consequence the tritium retention which could pose a serious risk for ITER operation and maintenance. It is, therefore, important to understand the adsorption mechanism of ammonia on surfaces, investigate when the surface saturation occurs and whether ammonia adsorbs as a molecule or undergoes a dissociation on the surface. In this contribution, ammonia sticking on different fusion-relevant materials is presented. The results show a pressure-dependent ammonia sticking on tungsten, boron and stainless steel followed by a partial desorption from these surfaces while on gold and beryllium, ammonia molecules weakly adsorb and completely desorb. A detailed explanation of the two interaction mechanisms is addressed. Furthermore, the time dependence of ammonia desorption as well as the chemical state of non-desorbed residuals were investigated with X-ray Photoelectron spectroscopy. Tungsten, boron and stainless steel surfaces showed a continuous dissociation process from $\mathrm{NH}_{3}$ to $\mathrm{NH}_{2}, \mathrm{NH}, \mathrm{N}$ and surface nitrides.
\end{abstract}




\section{Introduction}

In a fusion device, power from the core plasma has to be exhausted by the plasma-facing components, mainly in the divertor area, a special area of the plasma chamber where the open magnetic field lines intersect the primary plasma-facing components and where the plasma is neutralized and pumped away. In ITER, impurities will be seeded into the edge plasma to radiate $60 \%$ of the incoming power and reduce heat loads onto the divertor plates to values compatible with the divertor power handling capabilities [?]. Seeding gases that are currently under investigation in divertor tokamaks like JET (Joint European Torus), ASDEX Upgrade (Axially Symmetric Divertor Experiment) and foreseen for ITER are nitrogen $\left(\mathrm{N}_{2}\right)$, argon $(\mathrm{Ar})$ and neon $(\mathrm{Ne})$ or a mix of them. $\mathrm{N}_{2}$ is the preferred seeding species because of its favourable radiative properties [?]. Moreover, $\mathrm{N}$ seeding was shown to lead to improved confinement (and hence performance) in fullmetal tokamaks such as JET-ILW (JET ITER-Like Wall) and ASDEX Upgrade [?, ?]. Compared with $\mathrm{Ar}$ and $\mathrm{Ne}, \mathrm{N}_{2}$ radiates at lower temperature and, therefore, closer to the divertor plates, thus not degrading the confined plasma. However, once dissociated, $\mathrm{N}$ atoms chemically react with $\mathrm{H}$ and its isotopes $(\mathrm{D} / \mathrm{T})$ to form ammonia $\left(\mathrm{NH}_{3}\right)$ isotopologues. In ASDEX Upgrade, up to $8 \%$ of the injected $\mathrm{N}_{2}$ was converted into $\mathrm{NH}_{3}[?, ?]$ and laboratory experiments have shown that even higher levels of N-to- $\mathrm{NH}_{3}$ conversion (more than 10\%) were possible in low-temperature plasmas [?,?].

The formation of large quantities of tritiated $\mathrm{NH}_{3}$ has consequences for several aspects of the ITER operation and maintenance. In particular, cryopump would need more frequent regeneration that would limit ITER operational cycle. Since $\mathrm{NH}_{3}$ is a polar molecule, it can be easily adsorbed on metallic surfaces [?,?] and in particular on ITER first-wall material beryllium (Be), divertor material tungsten (W) and on the vacuum vessel and pipework made of stainless steel (SS). The in-vessel T inventory in ITER is limited to $1 \mathrm{~kg}$ [?] for safety reasons and the formation and sticking of large quantities of tritiated ammonia could contribute to the overall inventory while the recovery of $\mathrm{T}$ from $\mathrm{ND}_{2} \mathrm{~T}$ is still an open issue. Furthermore, the formation reaction of ammonia in tokamaks and the sticking of the formed ammonia on fusion-relevant surfaces is not fully understood. Quantification of $\mathrm{NH}_{3}$ sticking is, therefore, of considerable importance and will be studied on Be, W and SS surfaces in this paper. Boron (B) and gold (Au) surfaces will be investigated as well. The former element is largely used in tokamaks to decrease the oxygen $(\mathrm{O})$ content (boronization) [?] while the latter can be used as a reference.

In the literature, several studies [?, ?, ?, ?, ?] agreed on $\mathrm{NH}_{3}$ molecule interaction mechanisms with $\mathrm{W}$ through chemisorption and decomposition on $\mathrm{W}$ surface. On $\mathrm{Au}$ surfaces, however, it is still not clear if $\mathrm{NH}_{3}$ molecules weakly chemisorb or physisorb [?]. On $\mathrm{B}$ and Be surfaces, $\mathrm{NH}_{3}$ sticking was never investigated. Only calculations based on quantum density functional theory (DFT) [?] were performed to investigate molecular and atomic $\mathrm{N}$ reactions. In his calculation, A. Allouche et al. showed that $\mathrm{NH}_{3}$ does not stick on a Be surface. On SS surfaces, A. de Castro [?] and Neuwirth [?] indirectly investigated $\mathrm{NH}_{3}$ sticking by performing a gas balance analysis of $\mathrm{NH}_{3}$ injected in a $\mathrm{SS}$ 
vacuum vessel. Even though in both studies strong $\mathrm{NH}_{3}$ retention was observed, there is still considerable ambiguity with regard to the interaction mechanism of this molecule with the surface. In fact, Neuwirth et al. explained the $\mathrm{NH}_{3}$ interaction with the metal by a decomposition/chemisorption process while de Castro et al. claims that at $323 \mathrm{~K}$, a very large number of $\mathrm{NH}_{3}$ monolayers stick by physisorption (beyond $2000 \mathrm{NH}_{3}$ monolayers sticking that corresponds to $39.9 \mu \mathrm{g} / \mathrm{cm}^{2}$ of ammonia molecules retention on the wall). Furthermore, to our knowledge, there were no pressure dependence studies ever conducted on the materials used in this work. This is of prime interest for fusion as it allows to examine surface saturation; hence, maximum amount of ammonia that can adsorb on surfaces.

The present paper aims to investigate the interaction of $\mathrm{NH}_{3}$ molecules with $\mathrm{Au}$, W, SS, Be and B surfaces using a quartz microbalance (QMB) and X-ray photoelectron spectroscopy (XPS) techniques. For that, a detailed explanation of QMB theory and factors affecting its frequency shift will first be presented in section 3, along with a new calibration technique for the QMB. In section 4 a detailed $\mathrm{NH}_{3}$ adsorption/desorption study will be presented by examining the effect of both pressure and surface material on sticking. Finally, an XPS study to analyse the residual $\mathrm{NH}_{3}$ molecules sticking on the surface will be presented.

\section{Experimental setup}

The experiments were carried out in a SS vacuum chamber with a background pressure better than $5 \times 10^{-7}$ mbar. $\mathrm{NH}_{3}$ interactions with several surfaces was studied at different pressures in the range of $10^{-3}$ to 800 mbar. A thin film of the desired elements was first deposited on the QMB surfaces. For that, $20 \mathrm{~nm}$ of W, SS (containing $64 \%$ of Fe, $12 \%$ of $\mathrm{Cr}, 7 \%$ of $\mathrm{Ni}, 16 \%$ of $\mathrm{O}$ and traces of $\mathrm{Mo}, \mathrm{C}, \mathrm{Si}$ and $\mathrm{Cu}$ )), and $\mathrm{B}$ were deposited by magnetron sputtering technique. However, Be deposition (20 nm) was performed by the Thermionic Vacuum Arc (TVA) technique described in [?]. In fact due to the toxicity of Be, the deposition was not possible in our system and was done in INFLPR laboratory in Romania. Only the QMBs deposited with Be were exposed to air while the other materials were deposited and exposed to $\mathrm{NH}_{3}$ without breaking the vacuum. When the QMB reached a stable frequency (less than $0.1 \mathrm{~Hz}$ frequency change per $30 \mathrm{~min}), \mathrm{NH}_{3}$ gas was introduced through a leak valve from the gas line to the vacuum chamber after shutting the valves to pumps. The $\mathrm{NH}_{3}$ pressure was maintained for 30 minutes while the frequency of QMB was continuously monitored. During this time no wall outgassing effect was seen, i.e. after reaching the constant pressure and stopping the gas inlet no pressure increase was seen however this pressure was slightly decreasing due to the ammonia sticking on the walls. The pressure decrease caused by the SS wall pumping of ammonia was continuously corrected by introducing the gas in the chamber until reaching back the constant pressure. By registering the frequency change of the quartz, the mass of $\mathrm{NH}_{3}$ adsorbed on the surface can be determined using the method described in the section 3. A gas desorption step was then done by pumping the gas 
from the chamber and measuring the resulting frequency. After the desorption process, samples were transferred without breaking the vacuum to the XPS chamber for chemical analysis at several time intervals.

To verify the reproducibility of the results, all measurements on $\mathrm{W}$ surfaces were performed twice and two adsorption/desorption cycles were repeated for SS, B and Au for one fixed pressure. Furthermore, to verify the accuracy of each new installed QMB crystal, an Ar cycle at 50 mbar was done before each experiment. Although Ar does not adsorb on the surface at RT, there is still an effect on the quartz frequency change (explained later in section 4.1) that can be used to verify the QMB's accuracy. The standard error measured was equal to $0.09 \mathrm{~Hz}$ which indicates the accuracy of the QMB technique for our measurements. The error bars shown in Figure 5 were calculated by taking the two above mentioned points into account (50 mbar Ar cycle and experiment repetition). The QMB crystals used are AT-cut piezoelectric quartz crystals (6 MHz resonance frequency) with deposited Au electrodes purchased from Inficon. The QMB was connected to a $6 \mathrm{MHz}$ oscillator circuit (Inficon OSC-100 Oscillator). A frequency counter (Agilent 53132A Universal counter) was used to monitor the QCM oscillation frequency.

For the XPS characterization, samples were transferred without breaking the vacuum. The ultra-high vacuum (UHV) chamber is equipped with a monochromatic Al-K $\alpha$ X-ray source $(\mathrm{h} \nu=1486.6 \mathrm{eV})$ and a photoelectron spectroscopy analyzer (VG ESCALAB 210) with an energy resolution of $0.5 \mathrm{eV}$ at $20 \mathrm{eV}$ pass energy. The Au $4 \mathrm{f} 7 / 2$ peak was set to $84 \mathrm{eV}$ for electron binding energy (BE) calibration. Fitting of the core level lines was performed using DoniachSunjic functions [?] after a Shirley background subtraction [?], using UNIFIT for Windows (Version 2015) software [?]. The intensities were corrected using Scofield sensitivity factors and the transmission function measured with our system as described in [?].

To characterize the roughness of the bare crystals before deposition and also of the deposited layers, a Tencor 500 alpha stepper was used. The average roughness $\left(\mathrm{R}_{a}\right)$ was obtained by averaging 10 measurements of $1 \mathrm{~mm}$ length.

\section{Parameters influencing the frequency change of a QMB}

\section{1. $Q M B$ Theory}

Measurement of the frequency change of a crystal due to the mass loading, $\Delta \mathrm{f}_{m}$, is the fundamental principle of operation of QMBs. However this frequency change is not only affected by the mass change but by 4 other factors. These factors can be classified into two groups; namely the physical parameters of the surrounding gas and the structural parameters of the crystal. The former includes the temperature, pressure, viscosity, and density of the surrounding fluid, whereas the latter involves the mass loaded on the crystal and the surface roughness of the crystal. The total frequency shift of the QMB 
can be written in the form:

$$
\Delta f=f-f_{0}=\Delta f_{m}+\Delta f_{T}+\Delta f_{P}+\Delta f_{\nu}+\Delta f_{r}
$$

where $\Delta \mathrm{f}$ is the shift of frequency from the fundamental value $\mathrm{f}_{0}, \mathrm{f}$ is the measured frequency of quartz, $\Delta \mathrm{f}_{m}, \Delta \mathrm{f}_{T}, \Delta \mathrm{f}_{P}, \Delta \mathrm{f}_{\nu}$ and $\Delta \mathrm{f}_{r}$ are frequency shifts related to mass loading, temperature change, pressure change, density/viscosity of the surrounding fluid and the roughness of the QMB surface respectively.

The response of the QMB to thermal changes was neglected in this work (i.e. $\left.\Delta \mathrm{f}_{T}=0\right)$. In fact, all our experiments were performed at room temperature (RT) with $\pm 0.4{ }^{\circ} \mathrm{C}$ temperature variation per day, implying less than $0.04 \mathrm{~Hz}$ frequency variation per adsorption/desorption cycle for the AT cut quartz crystal used in this work (1.3 Hz variation per degree between 15 and $45^{\circ} \mathrm{C}$ ). In addition to the temperature fluctuation around RT effect, the QMB vibration could also impact the quartz temperature. For a vibration at $6 \mathrm{MHz}$ with a $10 \mathrm{~nm}$ oscillation amplitude [?,?], we calculated a maximum temperature increase approximatively equal to $0.3^{\circ} \mathrm{C}$, thus negligible in this work.

The mass effect on the QMB frequency was first derived by Sauerbery [?] and is given by:

$$
\Delta f_{m}=\frac{-2 n f_{0}^{2}}{\left(\rho_{q} \mu_{q}\right)^{\frac{1}{2}}} \Delta m=-C_{m} \Delta m
$$

Where $\mathrm{n}$ is the number of faces of the crystal in contact with the gas, $\rho_{q}$ the density of the quartz $\left(\rho_{q}=2.648 \mathrm{~g} / \mathrm{cm}^{3}\right), \mu_{q}$ the shear modulus of quartz $\left(\mu_{q}=2.947 \times 10^{11} \mathrm{~g} / \mathrm{cm} \cdot \mathrm{s}^{2}\right)$, $\Delta \mathrm{m}$ the change in mass per unit area and $\mathrm{C}_{m}$ the mass sensitivity of the QMB. For our experiment, the gas is in contact with both sides of the QMB and $\mathrm{n}$ is thus fixed to two for Au bare crystals. For other materials (SS, W, B and Be), as the coating was done only from one side of the crystal, $\mathrm{n}$ is fixed to 1 and the mass of ammonia adsorbed on the $\mathrm{Au}$ back side was substacted from the total mass.

Both $\Delta \mathrm{f}_{P}$ and $\Delta \mathrm{f}_{\nu}$ terms are associated with the influence of the medium surrounding the quartz crystal. The effect of pressure can be described as the frequency change due to the hydrostatic pressure exerted on the crystal by a hypothetical gas of zero density. It represents the compression effect of an increasing pressure of the surrouding gas on the quartz crystal. Stockbridge [?] showed that the frequency increases linearly with increasing pressure $(\mathrm{P})$ for the case of gases up to pressures of 1 bar and can be written as:

$$
\Delta f_{P}=f_{0} \alpha P=C_{P} P
$$

where $\alpha$ is the proportionality constant and $\mathrm{C}_{P}$ is the pressure sensitivity of the crystal. Both terms are independent of the type of fluid in contact with the crystal. Considering the value of $\alpha$ proposed by Stockbridge for a $6 \mathrm{MHz}$ resonating crystal, the $\mathrm{C}_{P}$ calculated is equal to $6.28 \times 10^{-3}$. The density $\left(\rho_{f}\right)$ and viscosity $\left(\eta_{f}\right)$ of the surrounding fluid increase with increasing pressure at a given temperature, leading to an amplitude damping of the oscillating QMB and consequent frequency decrease. Kanazawa and 
Gordon [?] quantified the relation between the frequency shift $\left(\Delta \mathrm{f}_{\nu}\right)$ and the viscosity and density of the surrounding fluids:

$$
\Delta f_{\nu}=\frac{-n f_{0}^{2}\left(\rho_{f} \eta_{f}\right)^{\frac{1}{2}}}{\left(\pi f_{0}\left(\rho_{q} \mu q\right)\right)^{\frac{1}{2}}}
$$

While $\Delta \mathrm{f}_{m}, \Delta \mathrm{f}_{P}$ and $\Delta \mathrm{f}_{\nu}$ can be calculated directly using equations 2,3 and 4 , an analytical equation to precisely calculate $\Delta \mathrm{f}_{r}$ cannot be found in literature. $\Delta \mathrm{f}_{r}$ originates from non-uniform morphology of the surface, where gas can fill the cavities and holes of the crystal and thus increase the mass loading on the surface. In most experimental work published so far, the roughness effect was not taken into account and only few papers $[?, ?, ?]$ have addressed the problem of quantifying the contribution from the roughness to the total frequency shift. However, it was found that surface roughness can drastically affect the resonance frequency of quartz crystal in contact with fluids [?]. In the next part the method employed to derive $\Delta \mathrm{f}_{r}$ will be presented.

\subsection{Experimental methods for the determination of the frequency shift due to roughness}

Herein, we present a calibration method using non-adsorbing noble gases that will allow extracting the frequency shift caused by the sample roughness. Based on the ideal model for surface roughness from Urbakh et al. [?,?,?], and using a perturbation theory model for a slowly varying roughness surface [?,?], $\Delta \mathrm{f}_{r}$ can be written in the form:

$$
\Delta f_{r}=-0.5 C_{m} C_{r} \rho_{f}
$$

The slowly varying roughness condition for which this equation is applicable is valid when both the average lateral length of surface shapes (ridges and valleys) and the decay length (defined in [?]) is higher than the average height of the surface shapes.

In order to calculate $\Delta \mathrm{f}_{r}$ in equation 5 , the value of the roughness factor $\mathrm{C}_{r}$ should be determined. As shown in [?], for the particular case where the density of the adsorbing gas on the QMB is less than 0.2 g. $\mathrm{cm}^{-3}$ and the QMB roughness value is in the range of few nanometers to approx. $700 \mathrm{~nm}, \mathrm{C}_{r}$ can be written as:

$$
C_{r}=a_{1}\left(1+b_{1} \rho_{f}\right)
$$

where $a_{1}$ and $b_{1}$ are the constants assumed to be independent of the gas type and the surface material.

All the QMBs used in this study, either bare rough Au coated crystals (as received from the manufacturer) or coated with $20 \mathrm{~nm} \mathrm{W,} \mathrm{SS,} \mathrm{B} \mathrm{or} \mathrm{Be,} \mathrm{had} \mathrm{R}_{a}$ values comprised between 300 and $465 \mathrm{~nm}$. Also, for our working conditions, i.e. temperature and pressure, and for all gases used in this work, density values do not exceed $0.015 \mathrm{~g} . \mathrm{cm}^{-3}$. Therefore, equation 6 can be applied.

Replacing $\mathrm{C}_{r}$ in equation 5, $\Delta \mathrm{f}_{r}$ can be written as a second order polynomial as function of the gas density:

$$
\Delta f_{r}=-0.5 C_{m} C_{r} \rho_{f}=-0.5 C_{m} \rho_{f}\left(a_{1}\left(1+b_{1} \rho_{f}\right)\right)=B_{1} \rho_{f}+B_{2} \rho_{f}^{2}
$$


To determine $\mathrm{B}_{1}$ and $\mathrm{B}_{2}$ values, we measured $\Delta \mathrm{f}_{r}$ for 3 noble gases $\mathrm{Ar}, \mathrm{He}$ and $\mathrm{Ne}$ on a bare gold crystal. As these gases cannot adsorb at RT on any surface we can consider $\Delta \mathrm{f}_{m}=0$ and measure the total frequency shift. Then $\Delta \mathrm{f}_{r}$ is calculated directly by subtracting pressure and viscosity terms from the total frequency shift (see equation 1). $\Delta \mathrm{f}_{r}$ is plotted in Figure 1 as function of the gas density. Using a second order polynomial fit, $\mathrm{B}_{1}$ and $\mathrm{B}_{2}$ coefficients were extracted, allowing one to calculate $\Delta \mathrm{f}_{r}$ for $\mathrm{NH}_{3}$ gas.

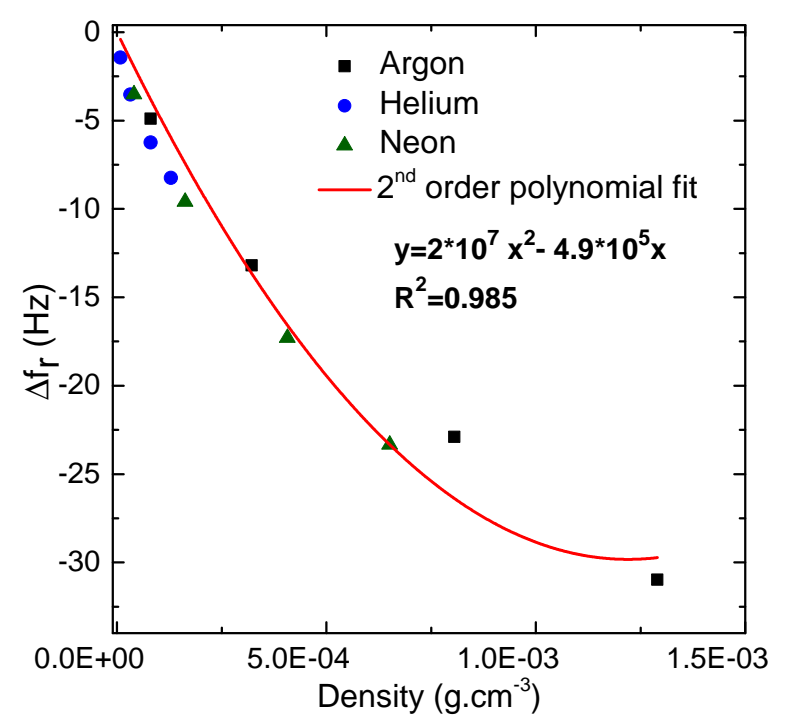

Figure 1: Frequency shift caused by the crystal surface roughness as function of gas density measured for Ar, He and Ne on Au surface fitted with a second order polynomial.

\section{Results and discussion}

\subsection{Interaction of $\mathrm{NH}_{3}$ with different materials}

$\mathrm{NH}_{3}$ adsorption/desorption cycles done at 50 mbar will first be presented on $\mathrm{Au}$ and $\mathrm{W}$ surfaces and compared to a reference Ar adsorption/desorption cycle done on $\mathrm{Au}$ (non-reactivity and zero adsorption at RT). The results of adsorption cycles of (a) Ar on $\mathrm{Au}$ bare crystal, (b) $\mathrm{NH}_{3}$ on $\mathrm{Au}$ bare crystal and (c) $\mathrm{NH}_{3}$ on $\mathrm{W}$ coated Au crystal are shown in Figure 2. The QMB total frequency shift as a function of time is represented by the black curve while the blue dashed line represents the calculated sum of $\Delta \mathrm{f}_{P}, \Delta \mathrm{f}_{\nu}$ and $\Delta \mathrm{f}_{r}$. As can be seen, the sum of the three terms is higher for Ar than $\mathrm{NH}_{3}$ due to the higher density of $\operatorname{Ar}\left(\rho_{A r}>\rho_{N H 3}\right)$. In fact, while $\Delta \mathrm{f}_{P}$ does not depend on the gas nature, $\Delta \mathrm{f}_{\nu}$ and $\Delta \mathrm{f}_{r}$ both increase with the gas density. The typical behaviour of a non-adsorbing gas $\left(\Delta \mathrm{f}_{m}=0\right)$ is shown in Figure $2 \mathrm{a}$. A sudden frequency decrease is observed when Ar was introduced. The vertical slope corresponds to the phase when the gas pressure is rising until reaching the constant value of 50 mbar. As the desired pressure is attained, the total frequency variation stabilizes and corresponds to the sum of pressure, roughness and viscosity effects on the QMB (blue dotted line). By pumping 
the gas from the vacuum chamber, these effects disappear and the QMB returns to its initial resonance frequency. As seen in Figure $2 \mathrm{~b}, \mathrm{NH}_{3}$ exhibits a different trend on $\mathrm{Au}$. The total frequency shift is much higher than the sum of $\Delta \mathrm{f}_{P}, \Delta \mathrm{f}_{\nu}$ and $\Delta \mathrm{f}_{r}$. According to equation 1 , this observation indicates that the observed frequency is mainly due to adsorbed mass on the surface. When the gas was fully pumped from the chamber, the QMB returns to its initial resonance frequency value, indicating a total desorption of $\mathrm{NH}_{3}$ molecules from the $\mathrm{Au}$ surface. The QMB coated with $\mathrm{W}$ behaves differently as can be seen in Figure 2c. In fact, the measured total frequency shift caused by the $\mathrm{NH}_{3}$ adsorption is around 3.5 times higher on $\mathrm{W}$ than on $\mathrm{Au}$ indicating that more $\mathrm{NH}_{3}$ can adsorb on the W surface. Moreover, after the pumping of the chamber, the initial resonance frequency was not reached and, as the base pressure is recovered, there is no residual $\mathrm{NH}_{3}$ in the vacuum chamber. This indicates that the partial frequency recovery can only be caused by remaining $\mathrm{NH}_{3}$ molecules on the QMB, i.e. a partial $\mathrm{NH}_{3}$ desorption.

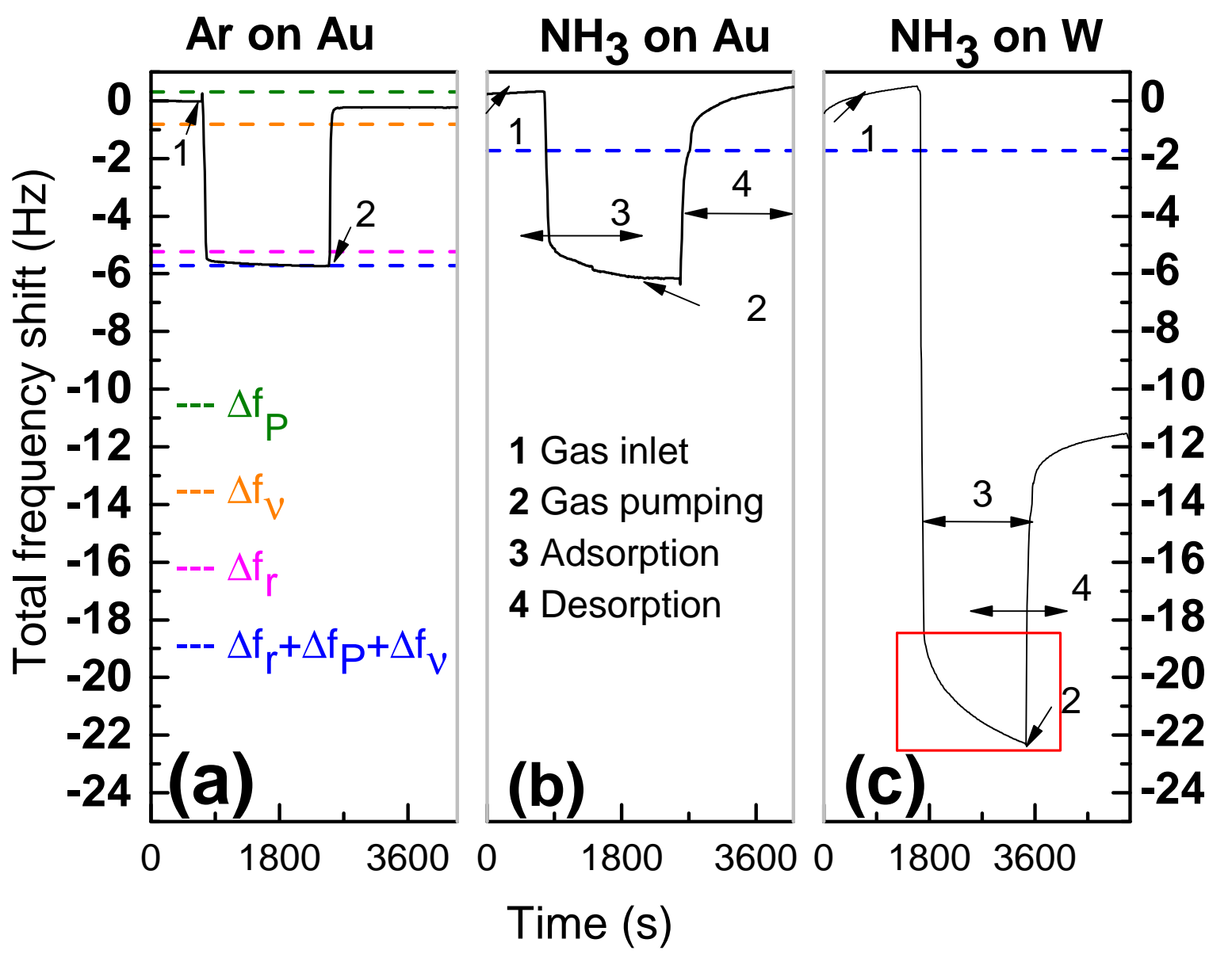

Figure 2: Total frequency shift as a function of time for adsorption/desorption cycle at 50 mbar of a) $\mathrm{Ar}$ on $\mathrm{Au}, \mathrm{b}) \mathrm{NH}_{3}$ on $\mathrm{Au}$ and c) $\mathrm{NH}_{3}$ on $\mathrm{W}$ surfaces.

Taking a closer look on the adsorption phase, one can notice that even though the 
pressure reached the desired value, the frequency continues to decrease for $\mathrm{NH}_{3}$ on $\mathrm{Au}$ or $\mathrm{W}$ with different slopes depending on the material. For clarifications, this phase was highlighted in Figure $2 \mathrm{c}$ with a red box. The slope is steeper on W than on Au surfaces, probably because of different adsorption kinetics of $\mathrm{NH}_{3}$ molecules on those surfaces. More information could be obtained by applying and adjusting a kinetic model to our results. Over the years, a wide variety of kinetics models have been proposed (Langmuir, Pseudo order 1, Pseudo order 2, Pseudo order n, Elovich, Crank, Boyd, Bangham, Weber and Morris...) [?] but none were used in this work as kinetics do not represent the main focus of this study. Yet, the adsorption equilibrium was not reached during the $30 \mathrm{~min}$ of exposure time and it is important to quantify the amount of $\mathrm{NH}_{3}$ molecules that is missing compared to the equilibrium case. By fitting the total frequency shift during $\mathrm{NH}_{3}$ adsorption on $\mathrm{W}$ with an exponential function, as shown in figure 3, it was found that the difference between the experimental frequency shift due to $\mathrm{NH}_{3}$ adsorption on W after 30 minutes and the calculated frequency shift at the equilibrium from fitting is equal to $0.24 \mathrm{~Hz}$. This value corresponds to approx. $1 \%$ of the total frequency shift measured after introducing the gas at 50 mbar. We can, therefore, assume that after 30 minutes, the adsorption is close to steady state.

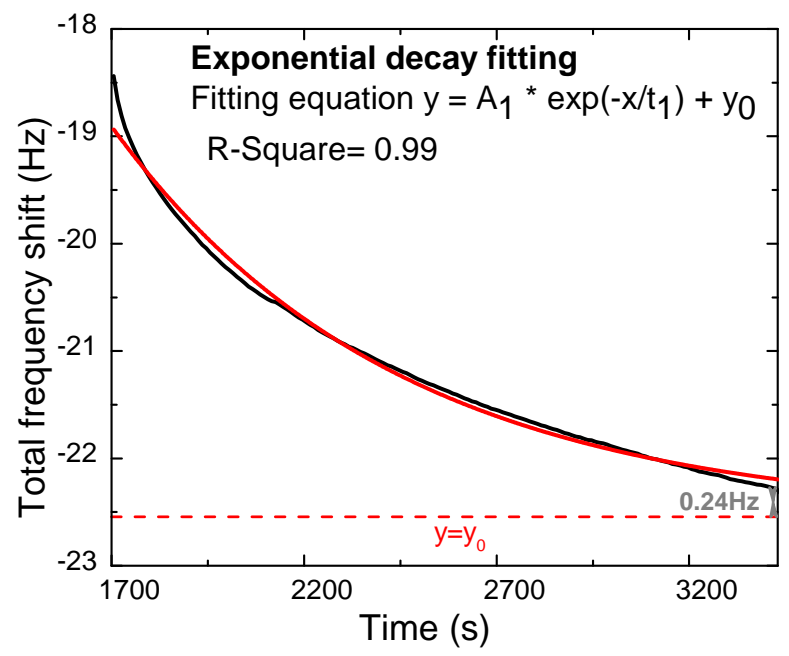

Figure 3: Total frequency shift as a function of time following $\mathrm{NH}_{3}$ adsorption at $50 \mathrm{mbar}$ on W surface for $30 \mathrm{~min}$. Red curves represents an exponential decay fitting for the measurement points.

In order to explain the difference in $\mathrm{NH}_{3}$ sticking between the studied materials we refer to their electronic structure. In ammonia, the $\mathrm{sp}^{3}$ hybrid orbitals of the central nitrogen atom is formed by the overlapping of three half-filled orbitals of nitrogen with s-orbital of 3 hydrogen atoms. There remains a full-filled $\mathrm{sp}^{3}$ hybrid orbital constituting one electronic doublet, lone pair. This doublet can be shared with an atom that has an empty orbital and thus form a polarized covalent bond, with a partial positive charge on nitrogen and a partial negative charge on the atom that has accepted the nitrogen electrons $\left(\mathrm{N}^{\delta+}-\mathrm{M}^{\delta-}\right)$. The strength of this chemical covalent bond is directly affected by the empty atomic orbitals on the surface as reported by Gundry and Tompk [?].

On $\mathrm{Au}$ surfaces, $\mathrm{NH}_{3}$ interaction is described as a weak chemisorption [?,?,?,?] 
arising from electron transfer from the $\mathrm{NH}_{3}$ lone pair orbital to the partially filled $\mathrm{Au}$ s band. Yet calculations done by Ante Bilic et al. [?], based on DFT showed that the charge transfer from $\mathrm{NH}_{3}$ to $\mathrm{Au}$ is minimal and the local densities of states and the charge distribution provide indication of poor covalent bonding, i.e. a dispersive interaction. Beside this dispersive and/or weak chemisorption of $\mathrm{NH}_{3}$ on the Au surface atoms, the low mass adsorption measured on gold, in our case, can be explained by another weak interaction. It consists of the $\mathrm{NH}_{3}$ interaction via one of its $\mathrm{H}$ atoms to an $\mathrm{O}$ atom adsorbed on the surface [?]. XPS measurements (presented later in section 4.3) of $\mathrm{Au}$ coated QMB exposed to $\mathrm{NH}_{3}$ showed that $11 \%$ of the Au surface atomic composition is physisorbed $\mathrm{O}$ (no chemical bond between surface oxygen and $\mathrm{Au}$ atoms). Therefore, the weak interaction of $\mathrm{NH}_{3}$ on $\mathrm{Au}$ can also be explained by $\mathrm{H}$ bond between $\mathrm{NH}_{3}$ and surface $\mathrm{O}$ atoms (purely electrostatic bond with lower energy that the covalent bond). On the other hand, $\mathrm{NH}_{3}$ strongly chemisorbs on electron acceptor surface atoms such as $\mathrm{W}$ with 4 electrons in the d orbitals, explaining the strong adsorption seen in Figure 2. It has to be pointed out that oxygen (from $\mathrm{H}_{2} \mathrm{O}$ mainly) is also present on the $\mathrm{W}$ surface and can interact with ammonia via $\mathrm{H}$ bond but the strong covalent bond between the metal and nitrogen of ammonia is the dominant interaction.

The $\mathrm{NH}_{3}$ adsorption showed that depending on the nature of the surface, $\mathrm{NH}_{3}$ can adsorb in mainly 2 different ways: (i) weak interaction consisting of a weak chemisorption and/or dispersive interaction with $\mathrm{Au}$ atoms and/or a $\mathrm{H}$ bonding to the surface $\mathrm{O}$ atoms. The three interactions are weak bonding and can be broken when pumping the gas from the surface, explaining, therefore, the complete desorption of $\mathrm{NH}_{3}$ from $\mathrm{Au}$ and (ii) a strong interaction where $\mathrm{NH}_{3}$ molecules stick on the surface via electron sharing involving $\mathrm{NH}_{3}$ lone pairs and the partially filled surface material valence bands. This results in a strong chemical bond and an incomplete desorption of the gas molecules from the surface after pumping.

\subsection{Pressure effect on $\mathrm{NH}_{3}$ adsorption/desorption process}

In order to investigate the effect of pressure on $\mathrm{NH}_{3}$ sticking, consecutive cycles of $\mathrm{NH}_{3}$ adsorption/desorption on Au, W, SS, B and Be (oxidized surface) were carried out with pressures ranging from $1 \times 10^{-3}$ to 800 mbar.

Note that for this consecutive cycle experiment, in order to make sure that the resulting equilibrium values at each fixed pressure are not affected by the previous amount of ammonia absorbed at earlier phases of the experiment, a freshly deposited $\mathrm{W}$ surface was exposed to a fixed ammonia pressure and compared to the amount of ammonia adsorbing on a previously exposed surface at lower pressure. Results showed that both amounts are equal indicating that a consecutive stepwise ammonia cycle on the same sample allows calculating the amount of ammonia adsorbed at each fixed pressure. The results of such consecutive cycles are shown for a $\mathrm{W}$ surface in Figure 4 and three main trends can be observed: (i) the total frequency decrease following the gas inlet $(\Delta \mathrm{f})$ is higher for each cycle at higher gas pressure, suggesting that the $\mathrm{NH}_{3}$ uptake 
increases with the pressure, (ii) the frequency shift after the gas pumping i.e the nondesorbed mass remains larger for a higher pressure and (iii) no saturation was reached up to 800 mbar.

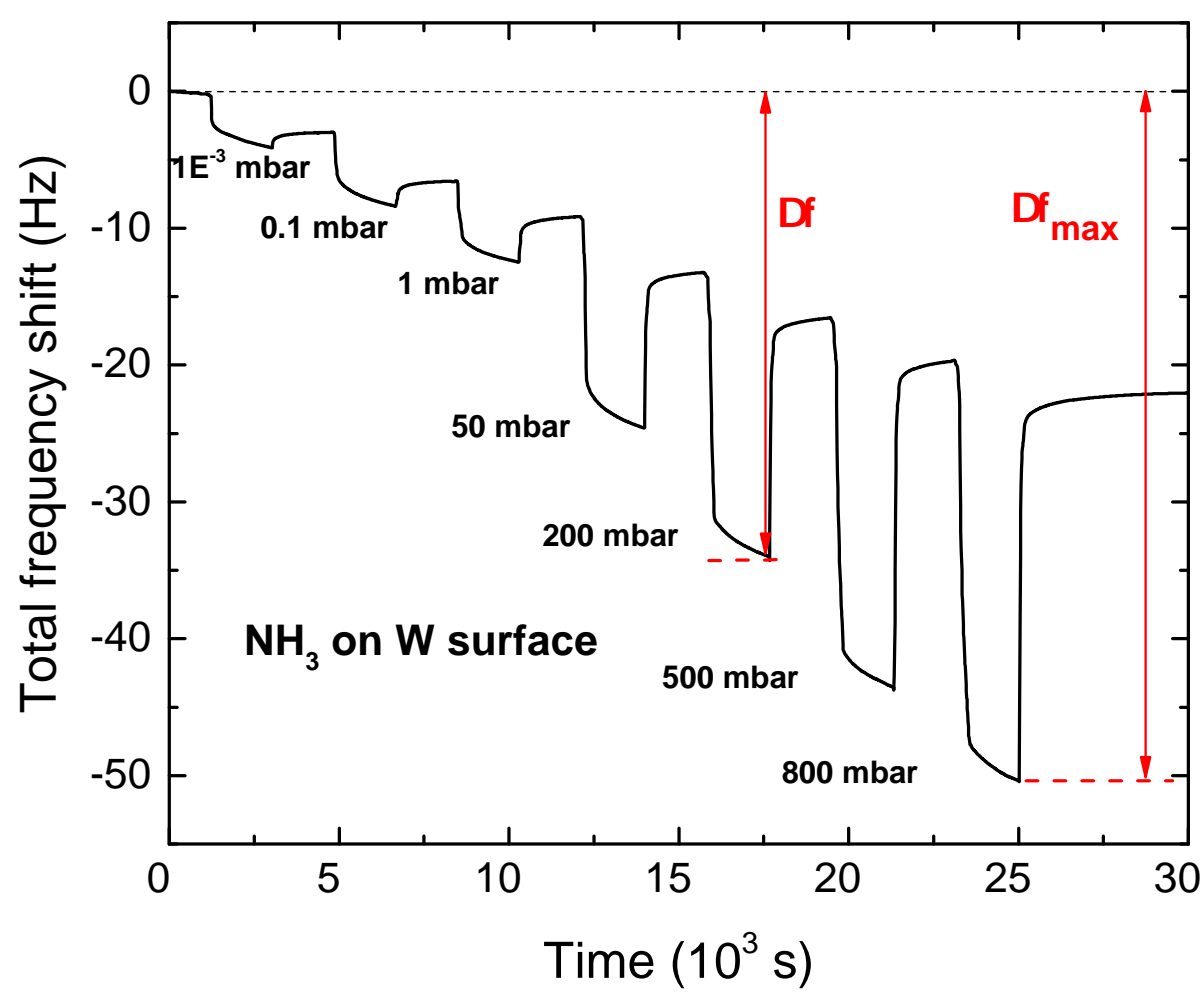

Figure 4: Total frequency shift $\Delta \mathrm{f}$ as a function of time for the adsorption/desorption consecutive pressure cycles of $\mathrm{NH}_{3}$ on a $\mathrm{W}$ surface.

The frequency change for each pressure was then extracted and the maximum value of the $\mathrm{NH}_{3}$ adsorbed mass was calculated according to the procedure described in section 3, after subtracting the roughness, viscosity and pressure effect. In order to convert this mass uptake into a number of monolayers (ML) adsorbed on the surface, the following calculations were done. Assuming one ML is equal to $6.2 \times 10^{14}$ molecules $/ \mathrm{cm}^{2}$ [?], the number of ML adsorbing on a surface can be calculated by dividing the number of gas molecules per surface area $\mathrm{N}_{N H 3}$ by one ML. $\mathrm{N}_{N H 3}$ can be calculated using the following equation:

$$
N_{N_{3}}=\frac{\Delta m}{M} \times N_{A}
$$

where $\mathrm{M}$ is the gas molar mass and $\mathrm{N}_{A}$ is the Avogadro number. We should note however that the number of ML can be overestimated as we assume a flat surface and neglect the effect of surface irregularities (steps, kinks...) on adsorption. Figure 5 represents the mass and number of $\mathrm{ML}$ of $\mathrm{NH}_{3}$ adsorbed on $\mathrm{Au}, \mathrm{Be}, \mathrm{B}, \mathrm{SS}$ and W surfaces. 

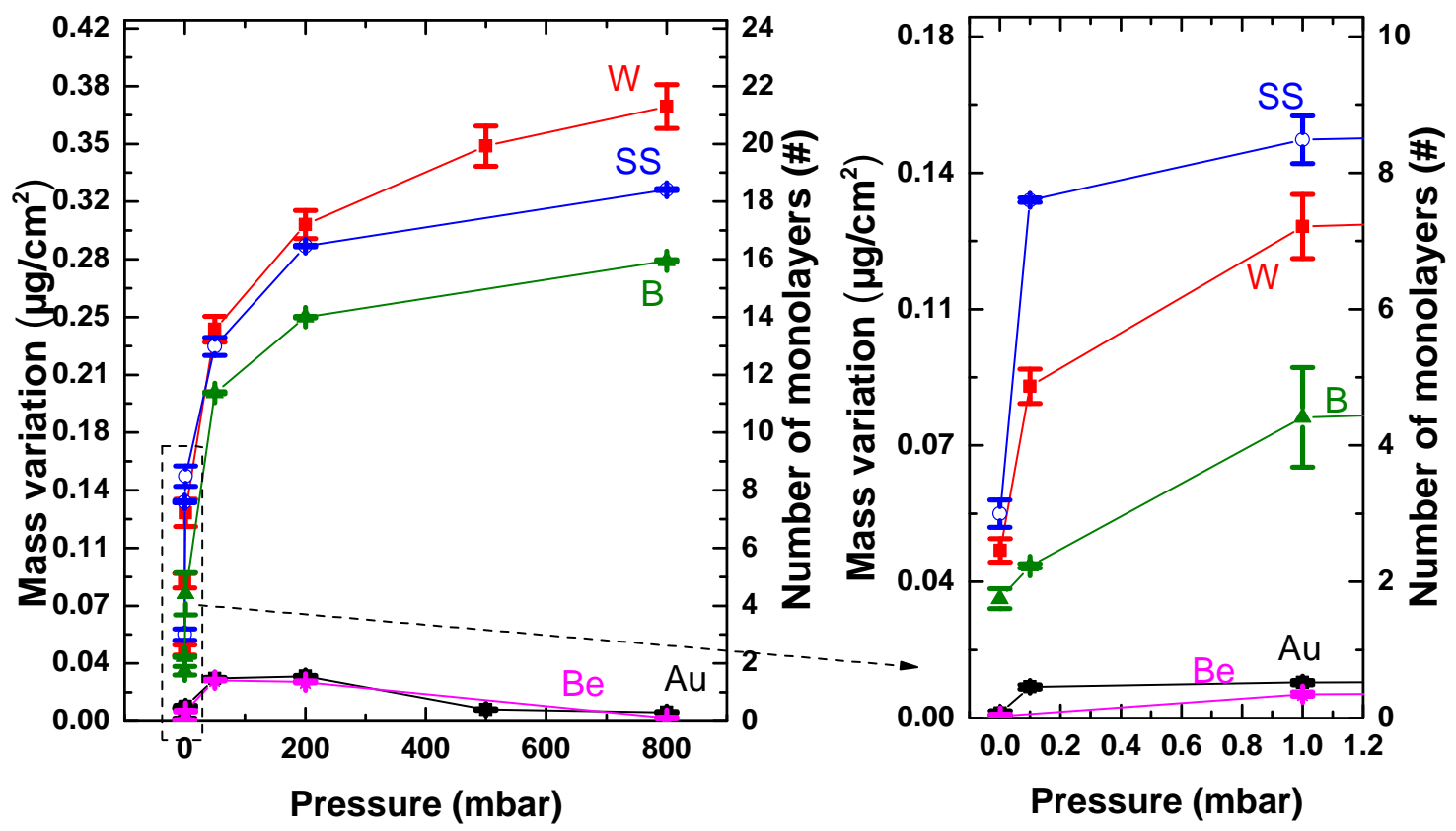

Figure 5: $\mathrm{NH}_{3}$ mass and number of ML adsorbed on W, SS, B, Au and Be surface after $180 \mathrm{sec}$ of ammonia exposure as a function of pressure.

Adsorption mechanism on $B e, B$ and $S S$ From Figure 5 two major interaction types are observed: a low mass uptake for $\mathrm{NH}_{3}$ on Be and Au surfaces that does not exceed $2 \mathrm{ML}$ and a high adsorption for $\mathrm{W}, \mathrm{B}$ and SS. As done earlier for $\mathrm{Au}$ and $\mathrm{W}$ in section 4.1 , the interaction mechanisms of $\mathrm{NH}_{3}$ on $\mathrm{Be}, \mathrm{B}$ and $\mathrm{SS}$ can be explained and classified in two categories. For SS and B surfaces, $\mathrm{NH}_{3}$ interaction exhibits a similar behaviour as $\mathrm{W}$ consisting of a high adsorption and a partial desorption. On the other hand, $\mathrm{NH}_{3}$ adsorption on Be surface was observed to be equal to $\mathrm{NH}_{3}$ adsorption on $\mathrm{Au}$.

For Be, the highest occupied orbital $\mathrm{s}$ is filled, making the surface non-reactive to $\mathrm{NH}_{3}$. A. Allouche et al. also confirmed that $\mathrm{NH}_{3}$ does not adsorb on the Be surface [?]. Yet, in our experiment, $\mathrm{NH}_{3}$ was found to adsorb on Be and can be explained by the presence of $\mathrm{O}$ on the surface. XPS measurements revealed $42 \%$ of $\mathrm{O}$ on the Be surface (both adsorbed and bonded to Be atoms forming oxides) and $\mathrm{NH}_{3}$ is known to bind to adsorbed $\mathrm{O}$ or to the metal atom for $\mathrm{BeO}[?]$. It should be noted that in the tokamak and precisely in the erosion zone Be will be only in metallic state. As for $\mathrm{Au}, \mathrm{NH}_{3}$ is weakly bound to the Be surface and can be fully desorbed when pumping the gas from the vacuum chamber. Similarly to $\mathrm{W}$, the three main constituents of SS, i.e. Cr, Fe and $\mathrm{Ni}$ possess electrons in the d orbitals (respectively 5, 6 and 8) and $\mathrm{NH}_{3}$ can thus strongly chemisorbs on this electron acceptor surface. The pressure dependence of the adsorption on the SS surface observed in figure 5 (higher than W for low pressure less than 1 mbar and lower than $\mathrm{W}$ at high pressures) cannot be explained yet.

Regarding $\mathrm{B}, \mathrm{NH}_{3}$ interacts with the surface through a strong covalently bonded Lewis 
adduct where the electron deficient $\mathrm{B}$ atoms represent the Lewis base and $\mathrm{NH}_{3}$, with its lone pair, plays the role of Lewis acid adsorbate. On $\mathrm{SS}$ and $\mathrm{B}$ surfaces, $\mathrm{NH}_{3}$ is thus strongly adsorbed and is only partially desorbing when the gas is pumped from the vacuum chamber.

Pressure dependence For $\mathrm{Au}$ and Be, the mass uptake increases with pressure until 200 mbar and then decreases for higher pressures which is still not understood. For W, $\mathrm{SS}$ and $\mathrm{B}$, the adsorbed mass increases with the $\mathrm{NH}_{3}$ pressure and no saturation was reached up to 800 mbar. At least $16 \mathrm{ML}$ were measured for B, SS and W surfaces at 800 mbar, indicating the formation of a multi-layered system.

The formation of multilayers is a result of the polarization of the $\mathrm{N}-\mathrm{H}$ bond as an intrinsic property of the ammonia molecule. In fact, nitrogen is more electronegative than hydrogen. Therefore, in the formation of $\mathrm{N}-\mathrm{H}$ bonds, the distribution of electrons in the molecular orbitals is such that the electrons are closer to the nucleus of nitrogen. A partial separation of charge generates and makes partially negative nitrogen and partially positive hydrogen. This permanent dipole and the particular shape (pyramidal) of the ammonia molecule generates intramolecular forces such that each monolayer binds successive molecular layers, similarly to what happens with water.

When ammonia molecule adsorbs on a metallic surface, this polarization effect could also be heightened. When a adsorbed molecule loses charge from the lone pair orbital to the surface atom, this local loss polarizes the $\mathrm{N}-\mathrm{H}$ bonds, causing the $\mathrm{H}$ to be even more positive, and increasing the strength of the H-bonds. This effect was confirmed by D.R. Jennison et al. for $\mathrm{NH}_{3}$ adsorption on Pt surface [?]. They have calculated an $\mathrm{H}$ bond energy of $0.38 \mathrm{eV}$ between the first adsorbed layer on the surface and the second layer of $\mathrm{NH}_{3}$ molecules, almost three times higher than that of the gas phase $\mathrm{NH}_{3}$ dimer $\left(\mathrm{NH}_{3}\right)_{2}$. When $\mathrm{NH}_{3}$ chemisorbs to Pt it donates electrons from the electron lone pair of the $\mathrm{N}$ atom to the empty $\mathrm{Pt}$ orbitals. The resulting increased polarization of the $\mathrm{NH}$ bonds in the first layer of $\mathrm{NH}_{3}$ molecules allows a second layer of $\mathrm{NH}_{3}$ molecules to form unusually strong $\mathrm{H}$ bonds. Furthermore, the multilayer formation of $\mathrm{NH}_{3}$ was shown previously on $\mathrm{W}[?], \mathrm{Ru}[?, ?], \mathrm{ZrB}_{2}[?], \mathrm{Ni}[?, ?]$ and SS [?] by different techniques.

Figure 6a illustrates this suggested mechanism where we present three intermolecular $\mathrm{H}$ bonds (red dashed bond in the figure) between $\mathrm{NH}_{3}$ molecules from each single layer. The decomposition fragments of $\mathrm{NH}_{3}$ shown in the same figure will be discussed in section 4.3 . 


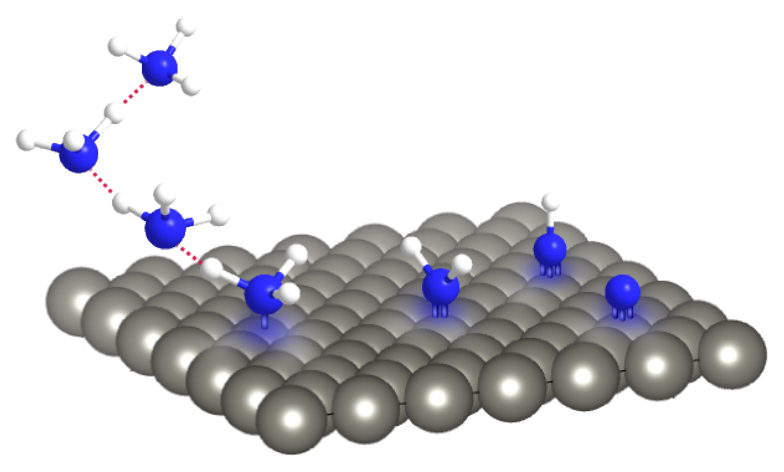

Figure 6: a) Multilayer formation of $\mathrm{NH}_{3}$ on the $\mathrm{W}$ surface through $\mathrm{H}$ bonds and b) $\mathrm{NH}_{3}$ decomposition species on surface. $\mathrm{N}$ and $\mathrm{H}$ atoms are respectively represented in blue and white. The red dashed lines represent intermolecular $\mathrm{H}$ bounds.

In the next section, XPS analysis of the non-desorbed $\mathrm{NH}_{3}$ will be presented.

\subsection{XPS study of non-desorbed $\mathrm{NH}_{3}$}

After the desorption process, samples were immediately transferred to the XPS chamber without breaking the vacuum. In Figure 7, the N1s core level spectra of Be and Au surfaces before ammonia exposure (only for Be, was not measured for $\mathrm{Au}$ ) and after the last $\mathrm{NH}_{3}$ absorption/desorption cycle (see Figure 4) is presented. As can be seen, no $\mathrm{N}$ peak was observed, indicating the absence of $\mathrm{NH}_{3}$ on both surfaces confirming, therefore, the total desorption discussed in sections 4.1 and 4.2 . 
Be before $\mathrm{NH}_{3}$

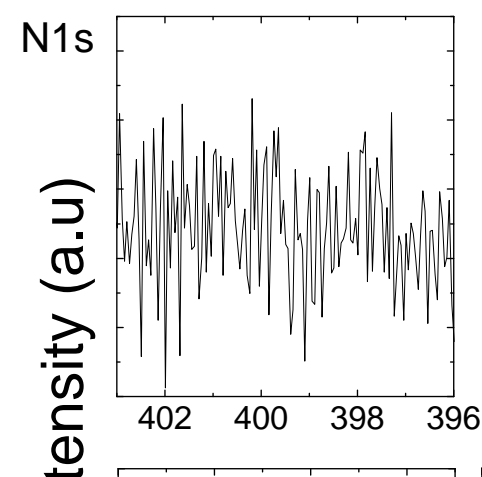

Be exposed to $\mathrm{NH}_{3}$ Au exposed to $\mathrm{NH}_{3}$
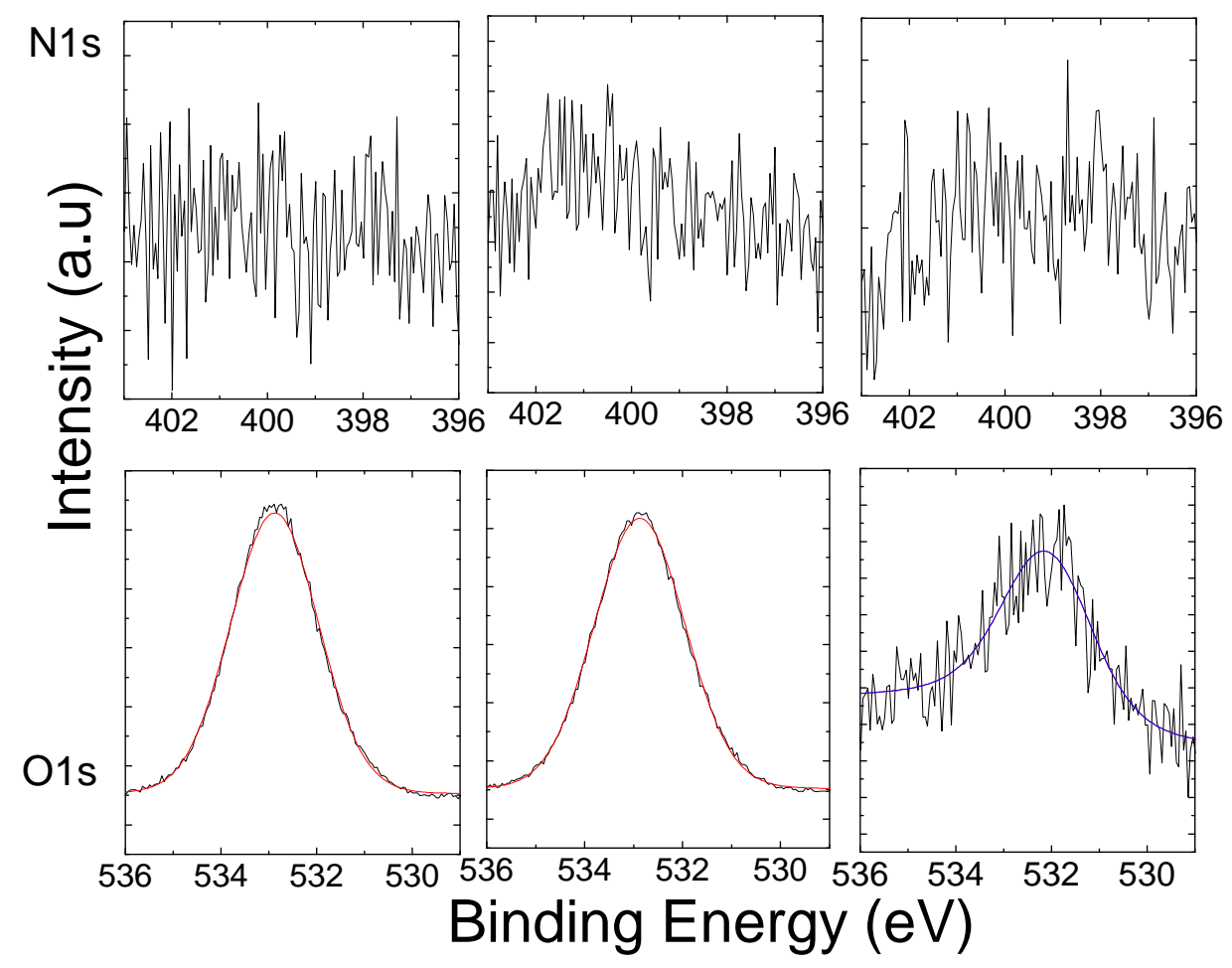

Figure 7: N1s (top) and O1s (bottom) core level spectra recorded before ammonia exposure on Be surface and 30 min after $\mathrm{NH}_{3}$ desorption from Au surface and Be surface.

For the other materials subject to strong $\mathrm{NH}_{3}$ adsorption, i.e. B, W and SS, XPS measurements performed before and after exposure of $\mathrm{NH}_{3}$ are shown in Figure 8 . The B surface (Figure 8 8 ) was composed of B (77.8\%), O (3.4\%), C (17.6\%) and N (1.2\%). The presence of $\mathrm{N}$ and $\mathrm{C}$ in the film is due to the fact that $\mathrm{B}$ atoms can easily catch species present on the vacuum vessel walls during deposition. The $\mathrm{B}$ was either in the form of a carbide $\mathrm{B}_{4} \mathrm{C}(187.4 \mathrm{eV})$ or of a nitride $\mathrm{BN}(190.4 \mathrm{eV})$ or bound to other $\mathrm{B}$ atoms $(188.4 \mathrm{eV})[?]$. After exposure the $\mathrm{N}$ atomic percentage more than doubled from $1.2 \%$ to $2.7 \%$, highlighting the bonding of $\mathrm{NH}_{3}$ to the surface. I has to be pointed out that this increase can not be related to the number of ML observed in section 4.2 as XPS measurement were done after the chamber pumping (ammonia desorption from the sample) and sample transfer. On the other hand, despite the presence of $\mathrm{O}$ and carbon $(\mathrm{C}$ ) on the surface no BCNO (at $191.9 \mathrm{eV}$ ) nor BO (at 192-192.7 eV) [?] were measured.

On the SS surface, Cr2p, Fe2p, and Ni2p core level spectra were measured before and after $\mathrm{NH}_{3}$ exposure. No change in $\mathrm{Ni}$ and Fe peaks were observed and this is probably due to the preferential reactivity of ammonia only with the highest electron acceptor metal of the SS which is the $\mathrm{Cr}$ (6 valence electrons missing compared to 4 and 2 for $\mathrm{Fe}$ and Ni respectively). Cr2p peak is, therefore, shown in Figure $8 \mathrm{k}$. Before $\mathrm{NH}_{3}$ 
exposure, the $\mathrm{Cr}$ was measured in a metallic state $\left(\mathrm{Cr}^{0}\right.$ at $\left.574.2 \mathrm{eV}\right)$ and in two different oxidic states: $\mathrm{Cr}^{+3}$ in $\mathrm{Cr}_{2} \mathrm{O}_{3}(576.2 \mathrm{eV})$ and $\mathrm{Cr}^{+6}$ in $\mathrm{CrO}_{3}(578.2 \mathrm{eV})$ [?]. After $\mathrm{NH}_{3}$ exposure, another peak was identified at $575.1 \mathrm{eV}$ and could be assigned to $\mathrm{Cr}$ bound to $\mathrm{N}\left(\mathrm{CrN}, \mathrm{Cr}_{2} \mathrm{~N}\right.$ or $\left.\mathrm{CrN}_{x} \mathrm{O}_{y}\right)[?, ?]$. This hypothesis is further supported by the absence of changes in the O1s core level spectra, indicating that the $\mathrm{Cr}$ peak at $575.1 \mathrm{eV}$ is a sign of $\mathrm{Cr}-\mathrm{N}$ bonding rather than $\mathrm{Cr}-\mathrm{O}$ bonding.

The $\mathrm{W}$ surface was fully metallic before $\mathrm{NH}_{3}$ exposure as shown in Figure $8 \mathrm{e}\left(\mathrm{W}_{4} \mathrm{f}_{7 / 2}\right.$ at $31.1 \mathrm{eV}$ ) [?]. W exposure to $\mathrm{NH}_{3}$ resulted in the formation of $\mathrm{W}$ nitride with a peak assigned at $32 \mathrm{eV}[?]$. Similarly to $\mathrm{B}$, no $\mathrm{W}$ oxides were measured at the surface despite the presence of $10 \% \mathrm{O}$ on the surface, indicating that the $\mathrm{O}$ is only adsorbed on the surface and not bonded to $\mathrm{W}$ atoms [?]. Furthermore, no oxonitrides peaks were observed at $33.5 \mathrm{eV}\left(\mathrm{W}_{4} \mathrm{f}_{7 / 2}\right)$ and $35.71 \mathrm{eV}\left(\mathrm{W}_{4} \mathrm{f}_{5 / 2}\right)$ [?].
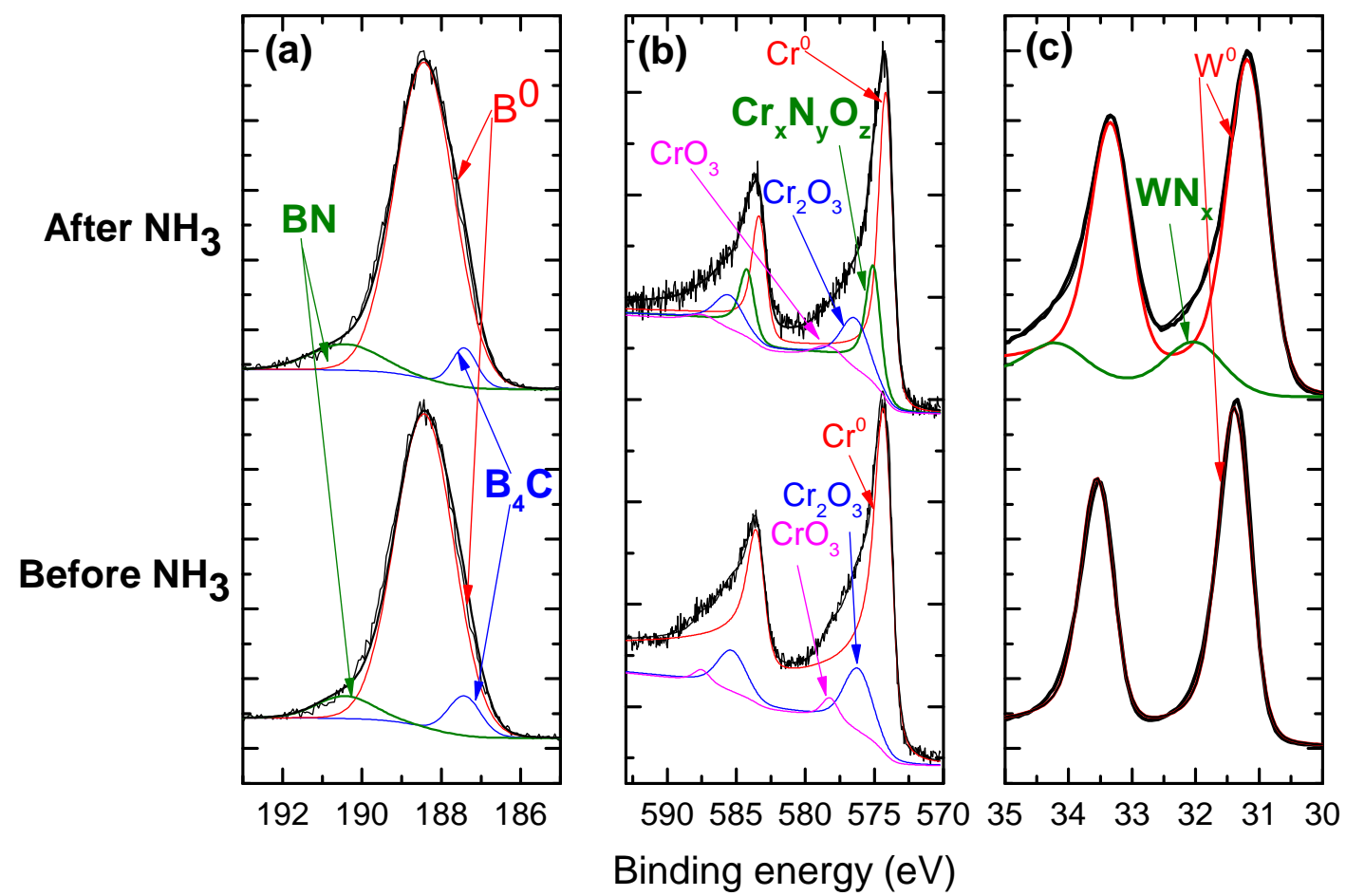

Figure 8: B1s, W4f and Cr2p core levels spectra recorded before $\mathrm{NH}_{3}$ exposure and 30 min after $\mathrm{NH}_{3}$ desorption from a) B surface, b) SS surface (only $\mathrm{Cr}$ is shown) and c) W surface. The red, green, blue and magenta solid curves are the individual chemical states. Solid black curves are the raw data and the sum curves.

In addition to XPS measurements performed 30 min after $\mathrm{NH}_{3}$ exposure, $\mathrm{N} 1$ s core level spectra were recorded at different time intervals ranging from $30 \mathrm{~min}$ to one week after the $\mathrm{NH}_{3}$ exposure. In between measurements, the samples were kept in the XPS vacuum chamber at $10^{-10}$ mbar. Results are shown in Figure 9 and the measured 
binding energy (BE) of the different chemical species are summarized in Table1. B was the sole surface containing $\mathrm{N}$ before the $\mathrm{NH}_{3}$ exposure with 2 peaks located at 397.8 and $399.0 \mathrm{eV}$, the former corresponding to $\mathrm{CN}$ and the latter resulting from $\mathrm{B}-\mathrm{N}$ bounding.
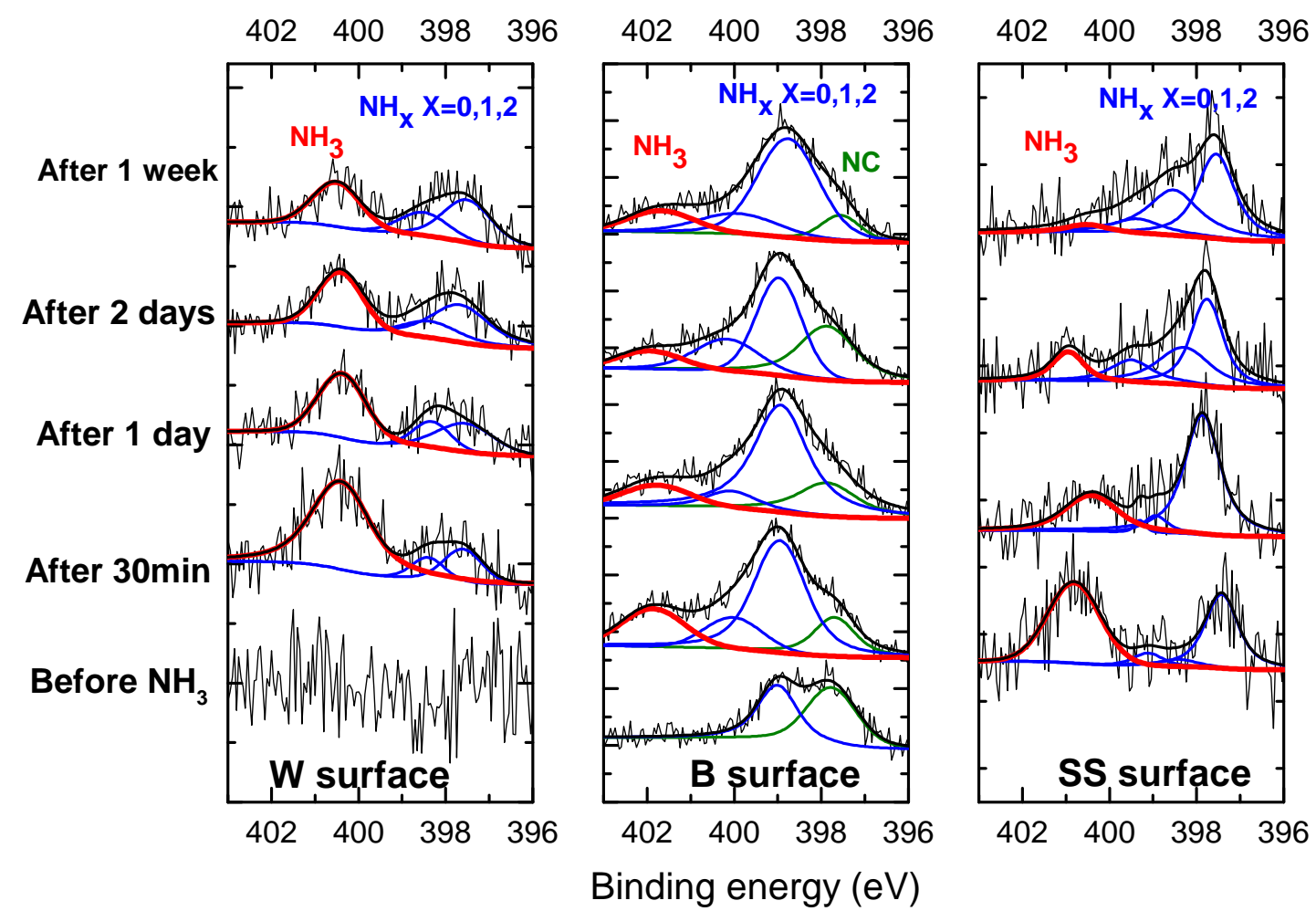

Figure 9: N1s core level measurements for the W, B and SS surfaces performed before and after $\mathrm{NH}_{3}$ exposure. The red curves are the individual peaks assigned to $\mathrm{NH}_{3}$ while the blue curves stand for the individual peaks assigned to $\mathrm{NH}_{x}(\mathrm{x}=0,1$ and 2). The black curves are the raw data and the sum curves.

After $\mathrm{NH}_{3}$ exposure, the $\mathrm{N} 1 \mathrm{~s}$ core level spectra on the $\mathrm{W}$ surface can be decomposed in three peaks corresponding to a second layer of $\mathrm{NH}_{3}, \mathrm{NH}_{2}, \mathrm{NH}$ and/or surface nitrides (see Table 1). With ongoing waiting time, the decomposition products of $\mathrm{NH}_{3}$, e.g. $\mathrm{NH}_{x}$ (where $\mathrm{x}=0,1$ and 2), saw their peak intensities increase while the peak intensity of $\mathrm{NH}_{3}$ decreases, indicating a continuous decomposition of $\mathrm{NH}_{3}$ on the $\mathrm{W}$ surface. A similar decomposition process was found on the B and SS surface. All the peaks were identified to be $\mathrm{NH}_{3}$ and its decomposition products (except for $\mathrm{CN}$ on $\mathrm{B}$ surface at $397.7 \mathrm{eV}$ ), and the corresponding BE are given in Table 1. 
Table 1: N1s BE values extracted from XPS measurement on W, B and SS surfaces after $\mathrm{NH}_{3}$ exposure. Reference values from literature and the corresponding species were added to the table.

\begin{tabular}{|l|l|l|l|}
\hline Surface material & $\begin{array}{l}\text { XPS N1s BE measured } \\
(\mathrm{eV})\end{array}$ & XPS N1s peak BE from literature $(\mathrm{eV})$ & Species \\
\hline \multirow{4}{*}{$\mathrm{W}$} & $397.6-397.8$ & $397.6[?], 397.8[?]$ & $\mathrm{NH}$, surface nitride on $\mathrm{W}$ \\
\cline { 2 - 4 } & $398.3-398.5$ & $398.4[?]$ & $\mathrm{NH}_{2}$ on W \\
\cline { 2 - 4 } & 400.4 & $400.7[?]$ & second layer of adsorbed $\mathrm{NH}_{3}$ on $\mathrm{W}$ \\
\hline \multirow{4}{*}{$\mathrm{Cr}$} & $397.3-397.9$ & $397-397.8[?]$ & $\mathrm{CrN}$ \\
\cline { 2 - 4 } & $398.3-398.9$ & $398.6[?]$ & $\mathrm{NH}_{2}$ on $\mathrm{Cr}_{2} \mathrm{O}_{3} / \mathrm{Cr}$ \\
\cline { 2 - 4 } & $399.1-399.5$ & $399.0-399.8[?]$ & $\mathrm{CrN}_{x} \mathrm{O}_{y}$ \\
\hline \multirow{4}{*}{$\mathrm{B}$} & $400.4-401.0$ & $400.7[?]$ & $\mathrm{NH}_{3}$ on $\mathrm{Cr}_{2} \mathrm{O}_{3} / \mathrm{Cr}$ \\
\hline & 397.9 & $397.9[?]$ & $\mathrm{BN}$ on B \\
\cline { 2 - 4 } & $398.8-398.9$ & $398.7-398.9[?]$ & $\mathrm{NH}_{2}, \mathrm{NH}$ on B \\
\cline { 2 - 4 } & $399.9-400.1$ & $399.8-400.2[?]$ & $\mathrm{NH}_{3}$ on B \\
\cline { 2 - 4 } & $401.7-401.9$ & $401.7-402.1[?]$ & \\
\hline
\end{tabular}

The XPS measurements showed a continuous decomposition of $\mathrm{NH}_{3}$ into $\mathrm{NH}_{x}$ $(\mathrm{x}=0,1$ and 2$)$ species, in agreement with previous studies done on $\mathrm{W}[?, ?, ?, ?]$, $\mathrm{B}$ [?] and $\mathrm{Cr}$ [?]. The progressive dehydrogenation is schematized in Figure 6b, with $\mathrm{NH}_{2}, \mathrm{NH}$ and $\mathrm{N}$ bound to the surface. During of the dehydrogenation process of the ammonia on a metal surface, ammonia loses hydrogen atoms from $\mathrm{NH}_{3}$ to $\mathrm{N}$. During this process nitrogen changes the hybridization from $\mathrm{sp}^{3}$ (four orbitals direct along the corners of a tetrahedron, three bonds with hydrogen and one with metal $\mathrm{N}-\mathrm{M}$ ) to $\mathrm{sp}^{2}$ (three orbitals direct along the corners of an equilateral triangle, two bonds with hydrogen and two with metal $\mathrm{N}=\mathrm{M}$ ) to sp (three bonds with metal $\mathrm{N} \equiv \mathrm{M}$ ).

\section{Conclusion}

In summary, $\mathrm{NH}_{3}$ adsorption/desorption cycles performed on bare $\mathrm{Au}$ and on $\mathrm{W}, \mathrm{SS}$, $\mathrm{B}$ and Be coated quartz crystals showed that the adsorption process is pressure and material dependent. This material- dependent sticking in the fusion device would lead to a non-uniform distribution of adsorbed tritiated ammonia in ITER (highest on the W divertor and SS pump ducts).

The amount of $\mathrm{NH}_{3}$ molecules bound to the surfaces was found to increase with increasing pressures for B, SS and W. Regarding Au and Be surfaces, a smaller number of ML was measured at higher pressures (500 to 800 mbar). No saturation was observed up to 800 mbar for W, B, and SS. Therefore, the adsorption of tritiated ammonia on the fusion device wall divertor and pumping ducts would be cumulative from one operational cycle (issues with tritium limit in the device) especially on the stainless steel surfaces which are not directly exposed to plasma impact.

In order to explain the difference in the adsorption between materials, two types of interactions were presented. A strong adsorption on W, SS and B due to electron sharing between the $\mathrm{NH}_{3}$ and the surface, leading to a true chemical bond. This strong interaction led also to the formation of multilayers through $\mathrm{H}$ bonds. In this case, the 
desorption of the gas was not complete and a continuous decomposition of the $\mathrm{NH}_{3}$ on these surfaces was measured with XPS performed during several time intervals after the exposure.

On the other hand, a weak $\mathrm{NH}_{3}$ adsorption is assumed on $\mathrm{Au}$ and $\mathrm{Be}$ and explained mainly by the $\mathrm{H}$ bond with $\mathrm{O}$ present on the surface. For those two materials, the desorption was complete according to QMB measurements and confirmed through XPS analysis. The total desorption shown on Au makes it a possible option as a coating material for the low neutron heat load SS pumping ducts to decrease ammonia and therefore tritium retention on these surfaces.

\section{Acknowledgements}

This work has been carried out within the framework of the EUROfusion Consortium and has received funding from the Euratom research and training program 2014-2018 under grant agreement No 633053. The views and opinions expressed herein do not necessarily reflect those of the European Commission or of the ITER Organization. ITER is the Nuclear Facility INB no. 174. This paper applies new physics analysis related to tritiated ammonia formation which is not yet incorporated into the ITER technical baseline. The nuclear operator is not constrained by the results presented here. The authors would like to thank the Swiss Federal Office of Energy, the Swiss Nanoscience Institute, the Swiss National Science Foundation and the Federal Office for Education and Science for their financial support. We are also grateful to Prof. Catherine Housecroft for her help and to Sara Freund for the schematic figures of molecules on surfaces.

\section{References}

